\title{
Retraction Note to: Diagnostic value of atypical lymphocytes in cerebrospinal fluid from adults with enteroviral meningitis
}

\author{
Yoshihiro Sato $^{1,2} \cdot$ Yoshitaka Ohta $^{3} \cdot$ Yoshiaki Honda $^{2} \cdot$ Masahide Kaji $^{2} \cdot$ Kotaro Oizumi $^{2}$
}

Published online: 10 July 2019

○) Springer-Verlag GmbH Germany, part of Springer Nature 2019

\section{Retraction Note: J Neurol (1998) 245:598-602 https://doi.org/10.1007/ s004150050252}

The Joint Editors-in-Chief have retracted this article [1]. An investigation by Kurume University has not been able to establish what the appropriate authorship should be because one of the authors, Yoshihiro Sato, is now deceased. As the appropriate authorship cannot be determined the Editorsin-Chief no longer have confidence in this article. Kurume University has also stated that it has not been possible to verify the data presented as none of the research material is available for investigation. We have not been able to contact Yoshitaka Ohta, Yoshiaki Honda, Masahide Kaji and Kotaro Oizumi about this retraction.

\section{Reference}

1. Sato Y, Ohta Y, Honda Y et al (1998) J Neurol 245:598. https:// doi.org/10.1007/s004150050252

The original article can be found online at https://doi.org/10.1007/ s004150050252.

Yoshihiro Sato

y-sato@ktarn.or.jp

1 Department of Neurology, Kurume University Medical Centre, 155-1 Kokubumachi, Kurume 839-0863, Japan

2 First Department of Internal Medicine, Kurume University School of Medicine, Kurume 830, Japan

3 Department of Pathology, St. Mary’s Hospital, Kurume 830, Japan 